\title{
Work-life balance, retention of professionals and psychological empowerment: an empirical validation
}

\author{
Ansumalini Panda
}

School of Management, Dr. Vishwanath Karad MIT World Peace University, Pune, India, and

Chandan Kumar Sahoo

\section{School of Management, National Institute of Technology Rourkela, Rourkela, India}

\begin{abstract}
Purpose - This study aims to explore the relationship between work-life balance and employee retention by examining the mediating role of psychological empowerment among software firms based in India.

Design/methodology/approach - The study collected 283 responses by using a structured questionnaire and interview method. Structural equation modeling (SEM) was used to validate the hypothesized research model for examining the consistency and sturdiness of the study variables by applying AMOS 20 .

Findings - The result reveals that psychological empowerment partially mediates the relationship between work-life balance and the retention of professionals. This indicates that a high degree of psychological empowerment strengthens the relations between work-life balance and the retention of professionals.

Research limitations/implications - The research outlined a best-fit model of psychological empowerment as a partial mediator among work-life balance and the retention of professionals. The study presents a set of sensible and practical aspects where work-life balance and retention of professionals can aid in developing and generating commitment to the organization which could offer new insights for software professionals, managers and practitioners.

Originality/value - This study emphasized that psychological empowerment helps in enhancing dedication, loyalty, integrity, allegiance and trustworthiness among employees, thus playing a role between work-life balance and the retention of professionals.
\end{abstract}

Keywords IT industry, Psychological empowerment, Retention of professionals,

Structural equation modeling, Work-life balance

Paper type Research paper

\section{Introduction}

The Indian economy is currently witnessing a rapid increase in job opportunities in the information technology sector, where automation and computerization provide ample opportunity. The progressive growth in the economy has facilitated the creation of technology jobs in the information technology sector with attractive salary and other benefits. India has embarked upon a journey of software development and transformation with a vision to increase gross domestic product (GDP) and create a significant place in the world economy. Radical and innovative strategies are thus espoused by software firms to succeed in the face of the challenges of fierce competition and worldwide diversity.

(C) Ansumalini Panda and Chandan Kumar Sahoo. Published in European Journal of Management Studies. Published by Emerald Publishing Limited. This article is published under the Creative Commons Attribution (CC BY 4.0) licence. Anyone may reproduce, distribute, translate and create derivative works of this article (for both commercial and non-commercial purposes), subject to full attribution to the original publication and authors. The full terms of this licence may be seen at http:// creativecommons.org/licences/by/4.0/legalcode
Received 21 December 2020

Revised 20 April 2021 13 July 2021

6 September 2021 Accepted 20 September 2021 
EJMS

$26,2 / 3$

104

Irrespective of significant growth, Indian software companies are affected by the high pressure and unrelenting change which is a reflection of the following: excessive work pressure, time based targets, uncertainties, long and non-standard working hours, major challenges faced by dual-earner couples, time pressure, and inexorable changes to increase efficiency and productivity (Cummings and Worley, 2009). These changes obstruct the balance between personal and the professional lives, leading to perplexity, stress and numerous pressures. These changes adversely affect the important personal and social life of the professionals, which in turn cause the negative spillover of work into homes, and home into work. This results in an imbalanced lifestyle, compromising the quality of employees' work-life, where the current situation demands the attraction of talent and retention of skilled, diligent, proactive and committed employees (Macey et al., 2009; Santhanam et al., 2021).

A healthy work-life balance is important for an individual's psychological well-being, where high self-esteem, satisfaction and overall sense of harmony in life can all be regarded as indicators of a successful balance between work and family roles. The psychological adjustment in terms of personality, motivation, perception, value, attitude and learning is most important for them to balance their work and family. Therefore, organizations need to focus on work as well as psychological aspects of their professionals, in order to stimulate positive attitudes and behavior through self-worth, self-esteem and positive identity in the workplace. Furthermore, individuals' psychological well-being includes high self-esteem, satisfaction and an overall sense of harmony in life, all of which can be regarded as indicators of a successful balance between work and family roles. Indeed, their work role should encompass the concepts of participative management, self-leadership and employee empowerment (Dewettinck and vanArneijde, 2011), so as to facilitate the ability of employees to exercise their full potential in achieving the organization's goals. Bearing in mind, this research focuses on the impact of psychological empowerment on work-life balance (hereinafter referred to as WLB), as this can retain talented software professionals. As psychological empowerment occurs when employees perceive that they exercise a certain level control over their work lives, or when they possess a perceived orientation towards their work (Spreitzer, 1995; Zoysa and Sivalogathasan, 2018). Empowerment is defined as being "intrinsic motivation by reflecting an individual's orientation to his or her work and family role." The objective of this research was to investigate the influence of WLB on employee retention by examining the mediating role of psychological empowerment. The hypothesis put forward is that psychologically empowered executives can use their full potential for obtaining satisfaction and positive outcomes in the organization, which, in turn, will be helpful in the long run to retain and attract competent professionals.

\section{The software industry: the Indian context}

The notable increase in globalization has provided an impulse for IT companies, which has unequivocally led to a flux of activity that effectiveness and the level of competence of managers. Radical and revolutionary strategies are espoused by software firms to succeed professionally in the face of the challenges of fierce and worldwide diversity. Accordingly, software firms based in India distressed as the result of high pressure and constant changes, with regular deadlines and augmented technology. For this reason, software firms have faced a problem of stressful jobs, a high attrition rate and a strained work-life (Sankar and Bhatnagar, 2010). In turn, this reflects low morale, less involvement and less commitment among professionals. WLB has thus originated as a key topic since the last decade, as it analyzes both employees' professional and personal life. WLB represents a paradigm of multidimensionality comprising the societal, corporeal, psychological and environmental magnitudes of a professional's ability to accomplish occupational and family commitments, in addition to other non-professional activities (Delecta, 2011). 
WLB is recognized as being a notable dimension to attract, maintain and retain the necessary professionals required to strengthen software organizations. Several scholars have placed emphasis on the research efforts carried out over decades where WLB has been connected with various outcomes and antecedents. This study analyzes both the direct and indirect relationships between WLB, psychological empowerment (PE) and retention of professionals (RPs), implicating that PE enhances professionals' sense of personal control, well-being as well as their quality of work-life (QWL) which results in high levels of organizational performance (Quinn and Spreitzer, 1997). WLB has also been considered to be a matter of well-being, whereas QWL refers more to professional life and family life. Few previous studies have been carried out connecting PE with WLB, which is a subject that has not been explored properly in the literature. It was established previously that $\mathrm{PE}$ acts as a mediating role between WLB and RPs. Accordingly, the main purpose of this research is to examine the various aspects of WLB that influence PE, which in turn helps increase the retention of software professionals. The objective of the study can thus be framed as follows:

(1) To find the connection between WLB and the RPs.

(2) To explore the relationship of PE with WLB and RPs, where PE acts as a mediator.
Work-life balance

\section{Conceptual background}

This section analyzes the relevant literature studies which focus on the relationship of those study variables ( WLB, PE and RPs) that are important to develop the hypotheses of the study. Various theoretical outlines on study variables exist (Zedeck and Mosier, 1990) which provide a link among them. These are connected with theories such as resource-drain, segmentation, spill-over, enrichment and work-family conflict. The spill-over and enrichment theory provides for the experience of the effect of one role on another (Morris and Madsen, 2007) which leads to improving work-life quality (Greenhaus and Powell, 2000). The segmentation theory relies on separate and unconnected roles which are not prejudiced by one another (Edwards and Rothbard, 2000). Accordingly, all these theoretical connotations are connected with all the study variables chosen for the study. The literature on WLB highlights several instances which explore a balanced approach of professionals fulfilling both their job and personal and family requirements. The study variables are based on the above-mentioned theories. Additionally, empirical analysis has been designed and applied to validate the hypothesized model.

\subsection{Key variables}

3.1.1 Work-life balance. The theme of WLB is framed as being a state of equilibrium where there is an equal demand for both individual's job and personal life. Greenblatt (2002) defined WLB as fulfilling the requirement among work and non-work demands. WLB is recognized as being one of the key emotional and psychological measures of whether employees feel committed and motivated in the face of global diversity and rigorous competition within an organization. WLB is identified as satisfaction with multiple roles in an individual's life (Clarke et al., 2004). WLB also comprehends desirable physical and psychological workplace so as to guarantee that professionals in satisfying their essential personal needs through their work experiences while achieving organizational goals (Brooks and Anderson, 2005). WLB attributes pleasure from professional lives only when the fundamental expectations about an employee's workplace and job are suitably fulfilled. Those professionals who experience stress from work/life conflict and both personal and professional demands are curtailed by unsatisfied perceptions of control and are less productive and committed in the organization and may be absent or even leave in their particular organization (Kohn and Schooler, 1983). 
EJMS

$26,2 / 3$

106

Perceived balance between work and one's social role can lead to satisfaction within life and PE. Researchers have focused both on work and personal content to measure WLB dimensions such as job satisfaction, work stress, working conditions, well-being, family interface and physical work environment (Van Laar et al., 2007). The study emphasizes the five factors of WLB, namely flexibility in workplace (Kossek and Lautsch, 2018), career progression and development (Neumann et al., 2018), financial and non-financial rewards (Lee et al., 2018), teamwork and communication (Sexton et al., 2017) and family and social support (Russo et al., 2016).

Flexibility at workplace: Galea et al. (2014) defined flexibility in the workplace as being basically the arrangements of working time by the mutual agreement of management and professionals which implies the scheduling of work flexibility to motivate professionals to achieve a better WLB, which subsequently leads to employees performing better within a lenient and flexible work pattern (Galea et al., 2014).

Career progression: Career development and talent management practices which positively affect WLB whereby high career perspectives can lead to the prioritization of work-life over the personal life of information technology (IT) professionals. Such professional's satisfaction could be improved if they perceive that they also have suitable domestic roles as well as strategic roles (Rogier and Padgett, 2004). Managing a career with a balanced view of the organization depends on the nature of the business environment (Jung and Takeuchi, 2018) as well as the acknowledged career development theory and valid practice (Baruch, 2006).

Teamwork and communication: Teamwork has generally produced synergy, where the possession of complementary skills increases the strengths, potential and competency of professionals. Communication between software organizations may generate the sharing of information, mutual and collaborative decision-making. In addition, the identification, encouragement and coordination of work efforts improve the degree of WLB (Propp et al., 2010).

Financial and non-financial benefits: Financial supports such as an increase in salary and benefits, organizing social and cultural activities, providing paid holidays and offering company sponsored holidays are all helpful in retaining the employees. Non-financial benefits such as career development, performance-based promotion and recognition for being excellent employees of the particular organization can all increase the level of self-esteem among employees (Cooke and Jing, 2009).

Family and social support: It has been proven to help professionals practice WLB, and can well increase positive energy at work and enrich the psychological aspect of professionals (Ross and Mirowsky, 2002). It has been found that work and family supports are important for the persuading professionals to achieve a balance both in work and life.

3.1.2 Psychological empowerment. The concept of empowerment is described as the psychological attitude of empowering executives, whose personality is viewed as the perception or attitude concerning their role and work in the organization (Miguel et al., 2015). The basic implication of empowerment is to increase one's capacity and authority to take any decision without any obstruction and that it improves one's performance in an organization and thus enhances the organizational productivity and individual motivation (Elmuti, 1997). Individual empowerment can be defined as being an emotion and a sense of perception regarding individual life. Primary research highlights the existence of sense of control which in turn has a direct consequence in the development of one's physical and mental health. PE occurs when professionals perceive that they can exercise a degree of control and balance in their professional life (Spreitzer, 1995). In addition, PE is defined as acquiring an intrinsic motivation exhibited by four types of recognitions like meaning, competence, selfdetermination and impact. Meaning is denoted as degree of objectivity and the resemblance of one's values in relation to connect to both the task in hand and 
organization (Thomas and Velthouse, 1990), whereas competence is seen to be the skillful conviction of work activities that replicate personal belief towards the ability and skill to be able to perform the task in hand. Empowered professionals feel that their task and degree of effort is highly significant and for this reason they are often concerned with what is called self-determination (Quinn and Spreitzer, 1997). Impact delineates an individual's capacity and belief to be able to encourage the system (administrative, strategic and operational decisions), which are rooted in the organization (Spretizer, 1997).

3.1.3 Retention of professionals. Akila (2012) stated that the RPs is well-defined as a course of action where executives are anticipated to remain in the same organization for the longer period of time or until they complete term of the job. RPs is defined as being an organized effort to foster and create an environment which inspires current executives to remain in employment through adoption of employee retention policies and practices which meet the diverse needs (Haider et al., 2015). Retention is one of the major issues in the IT sector, which defines the overall strategy and ability of the organization to retain competent professionals and maintain a low rate of turnover. An organization needs to design retention programs to overcome this emerging situation (McEvoy and Cascio, 1985) for those organizations that have a better work culture tend to possess better retention rates (Sheraiden, 1992). Mak and Scockel (2001) identified that organizations must implement career development programmes which orient employees to manage retention rates, according to the need and requirement of the organization. In their opinion of these authors, retention can be focused on the context of loyalty, turnover and exhaustion (Mak and Scockel, 2001). Deery and Jago (2015) focused on the adoption of four major organizational strategies to improve the level of RPs, namely work culture, work support and recognition, compensation and rewards, and compatibility and autonomy.

\subsection{Interrelationship among variables}

3.2.1 Work-life balance and employee retention. Retention is an effort to maintain a physical work environment that encourages current employees to remain in a particular organization. Employee retention policies are intended to address and fulfill the requirements of personnel to maximize their happiness and minimize the hiring and training costs of personnel (Iqbal and Hasmi, 2015). In today's highly competitive scenario, WLB is key topic which broadens and expands the family life and job responsibilities of working professionals (Lockwood, 2003). It has been proven that those members of the workforce who adhere WLB programs, think more strongly about remaining in same organizations for a maximum period (Landaur, 1997). In total, $60 \%$ of research have exhibited that those employees who have the capability to balance professional responsibility with family and personal responsibilities have a greater tendency to remain in the particular organization. WLB programs may demonstrate the probability to significantly increase employee morale, reduced absenteeism and retain a work force (Kanwar et al., 2009). WLB is capable of developing the level of motivation, satisfaction and the retention of a talented workforce to date has been made on the basis of unreliable and observed evidence (Pocock, 2005). Job attitudes and personal attributes such as job satisfaction and employee commitment affect perceived WLB and employee turnover both positively and negatively. Research has determined that WLB and managerial support can reveal professional intentions to stay or leave in a particular organization (Kanwar et al., 2009) indicating the practical and managerial implication that lack of managerial support and degree of WLB may negatively affect the intention to leave the organization. Cegarra et al. (2012) found that employee job satisfaction was a significant driver for WLB and employee retention. WLB programmes aim to increase the morale and motivation of a professional and to attract and retain executives by reducing absenteeism (Kanwar et al., 2009). WLB could 
EJMS

$26,2 / 3$

108 amplify the degree of inspiration, happiness and the ability to retain capable and talented professionals (Pocock, 2005). Hence, this study can be postulated as defending that:

H1. WLB is significantly connected with the RPS.

3.2.2 Work-life balance and psychological empowerment. Kanter (1977) revealed that selfempowered executives are well-fitted to meet the workplace challenges to overcome the perceptual gap between expected and actual working conditions. PE can improve the degree of WLB among executives since the professionals have control regarding high work pressure, family problems and fair treatments in their job. PE improves the sense of personal control and stimulates professionals to engage in work, which in return brings about positive organizational and managerial outcomes (Quinn and Spreitzer, 1997). Professionals increasingly experience the interference in their personal and working life, which in turn affects their psychological well-being and physical health (Vallone and Ensher, 1998). The well-being of professionals is receiving with high degree attention from communities and organizations. Recent research has demonstrated that both WLB and PE result in significant and positive interconnection which exercises a large influence on work-family related variables and physical health (Bond, 2004; Loretto et al., 2010). The practical aspect of the link between empowerment, and physical and psychological well-being can have direct effects on WLB (Friedman and Westring, 2015). When professionals feel empowered in a work situation, it tends to enhance their job productivity and efficiency (Akadag, 2012) and decreases absenteeism within the organization (Koberg et al., 1999). One study defines that PE tends to positively affect the psychological attitude and behavior towards work as well as perception of capability and roles within the organization. Both WLB and PE share the common parameters which define the subject's capability, life satisfaction and involvement within the organization setting (Ickes et al., 2018; Grealish et al., 2017). Kim and Beehr (2018) identified that PE is significantly connected with the work-life model as an antecedent of work-life. The above conversation has derived a hypothetical statement that:

H2. PE has a significant connection with the WLB of software professionals.

3.2.3 Psychological empowerment and retention of professionals. Psychologically empowered professionals are on the whole dedicated (Jha, 2010) and satisfied with the organization as well as with the job (Laschinger et al., 2010). Past research measured PE and its effect on organizational trust and job satisfaction together with employee commitment which has a strong and significant association with employee's intention to remain in a particular organization (Patrick and Laschinger, 2006). The aspects and dimensions of empowerment include employees' autonomy, accountability, information accessibility, resource availability, participative decision making and also meaningfulness in the workplace and its related to challenges (Pathak and Srivastava, 2017). If a professional is psychologically empowered, the resultant expectation is that they possess that freedom to express their ideas and tend to perform better in their job. Accordingly, psychological empowered human capital is fast becoming the prime ingredient for organizational success, and it has a positive effect on employee retention. In their research among police officers, Violanti and Aron (1994), found that high levels of job satisfaction were associated with improved psychological well-being. The relationship between low levels of job satisfaction and increased turnover behavior is consistently proven in the literature (O'Leary-Kelly et al., 1994), Nevertheless, empowerment stimulates professionals to perform well, reciprocates high degree of commitment and increases the level of commitment towards the organization. Several researchers have highlighted $\mathrm{PE}$ as a significant mechanism to develop sense of obligations among professionals, which results in high levels of work performance, job involvement, motivation and morale all of which reduced incidence of turnover intentions (De Klerk and Stander, 2014; Avolio, 1999; Yukl, 2010). Software organization encourages professionals to 
discover innovative methodologies through the use of problem solving, and the categorization of professional pre-requisites, which in turn leads to more engaged work performance, high commitment and a greater level of retention among professionals (Walumbwa and Lawler, 2003). PE replicates the continuing ebb and flow of the perception and attitudes of professionals towards their work organizations in relation to themselves (Robbins et al., 2002). The hypothesized relationship among the study variables is thus as follows:

H3. Focusing on PE has a significant effect on the RPs in the IT industry.

\section{Literature gap analysis and mediating variables}

Software professionals are the frontliners who work persistently to ensure better services and the timely delivery of projects. Their well-being and health is usually ignored in the process as these professionals often face psychological and physical pressures because it is they who have to resolve the challenging and complicated tasks in the workplace. WLB has thus become a significant approach not only for increasing demand of the contemporary business environment but also for the growing family structure (Russo et al., 2016). Furthermore, software organizations in India are required to design an appropriate intervention for executives. An organization can achieve a healthy WLB which can be characterized by empowerment, dedication and commitment among professionals. However, the organization needs to emphasize WLB in India's IT companies. Accordingly, the study has focused on the role of PE for enhancing both the degree of WLB and the mediating role of PE between WLB and retention. This represents a unique effort of researchers as very little of the aforementioned literatures studies with connection between WLB and RPs (Lockwood, 2003; Landaur, 1997; Kanwar et al., 2009) as well as PE and retentions, (Laschinger et al., 2010; Pathak and Srivastava, 2017; Walumbwa and Lawler, 2003). In this paper, the author has collected the literature studies, which support the objectives of the study. The previous research reveals the mediating effect of $\mathrm{PE}$ among other study variables such as self-control, burnout, job performance, team outcome, prestige and identification among others (Yilmaz and Ovunc, 2017; Kim et al., 2012; Sun, 2016; Meng et al., 2016).

The aforementioned literature and the Hypothesis 3 prominently portray that various studies exist which explore the connection of two constructs such as WLB, PE and RPs. The above discussion of the literature reveals that WLB is a certain outcome of employee retention as well as being a significant predecessor of PE. It can thus be implied that PE can act as a mediator between WLB and RPs. Few studies have explored examining the mediating role of PE (Pathak and Srivastav, 2017; Joo and Jo, 2017; Dust et al., 2018) with other study variables. However, the earlier literature is silent, when it comes to examining the mediating role of PE between the relationship of WLB and RPs. The present research of this paper emphasizes that professionals are capable of having a high level of empowerment, which may not directly convert into increasing the RPs, or the feeling of empowerment and satisfaction which could indicate the path towards better and healthy WLB. This paper thus represents an innovative effort of researchers to explore the relationship between above constructs, especially in case of IT companies in India. The study attempts to overcome the gap in the literature through empirical validation. Consequently, the hypothesized statement of study variables is anticipated as:

H4. PE mediates the connection between WLB and the RPs in the IT industry.

The hypothesized research model is found in existing literature and illustrates the fuleral point of this study, in that it represents the connection suggested from the related Hypotheses 1-4 (Figure 1).

Work-life balance 
EJMS

$26,2 / 3$

Figure 1.

Hypothesized

research model

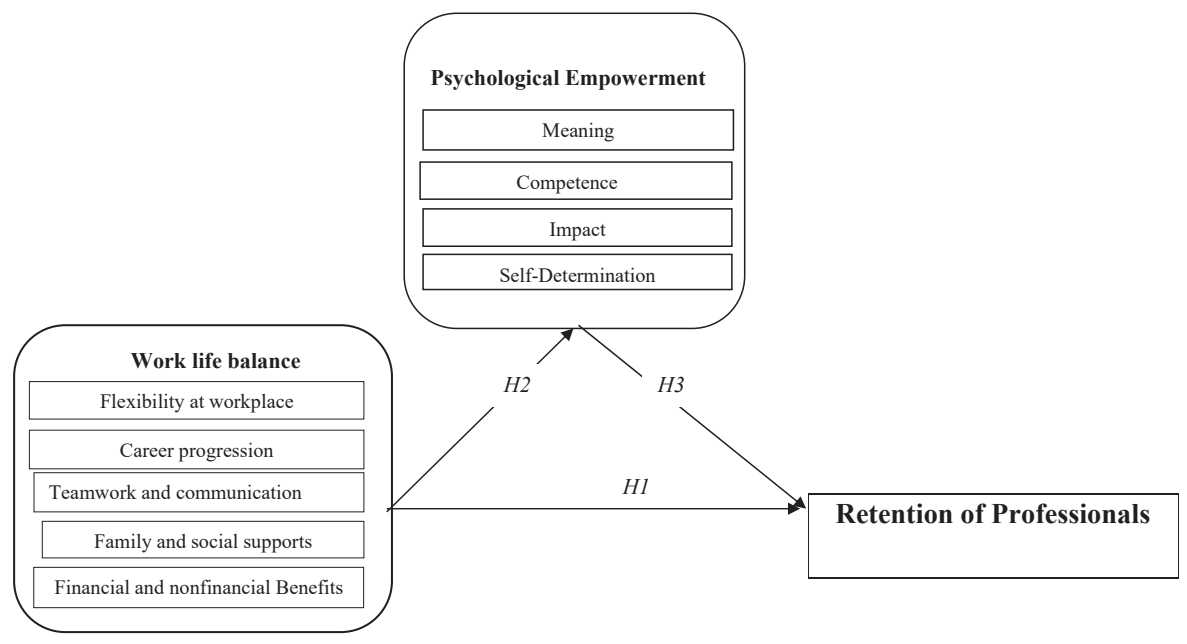

The hypothesized research model is derived from the outcome of various studies that are carried out as reported in literature reflecting the promising relationship that exists between the constructs (Figure 1).

\section{Research methodology \\ 5.1 Sampling}

The study adopted a descriptive research design method to examine the interaction of three fundamental variables, namely WLB, PE and RPs. Leading IT companies from different cities of India such as Tata Consultancy Services, Pune, Infosys Ltd, Bangalore, Wipro Ltd. and Mindtree Ltd., Hyderabad, were approached for the purpose of data collection and analysis as a part of this research. The target sample for this study is lower and middle level executives, including developers, software associates, project lead, team leader or project manager of the aforementioned software firms. The researcher contacted various executives covered under the sample, department heads, head of HR and team leaders of specific projects, and then conducted structured interviews with the above experts and distributed a questionnaire through Google-form via mail. Structured interview was conducted with senior executives such as team leaders, project managers and HR head and department head, across the table. The data analysis was carried out by using simple and stratified random sampling to choose respondents among a total of 380 self-administered questionnaires that were distributed among respondents, and which resulted in 283 valid opinions with concrete response rate of $74.47 \%$.

\subsection{Participant details}

The study received 283 valid responses of which $49.7 \%$ were male respondents and $50.3 \%$ female. The maximum participants were categorized by age ranging from 20 to 30 years (49.83\%) followed by $31-40$ years $(33.3 \%), 41-50$ years $(13.67 \%)$ and $51-60$ years $(3.17 \%)$. Of the total, $63 \%$ respondents were married and $37 \%$ were unmarried. Most of the respondents were lower level executives (53.4\%) with the remaining $46.6 \%$ being middle level and high level executives; and $39.5 \%$ of the participants were having professional experience of $0-5$ years, followed by $5-10$ years $(35.2 \%), 11-15$ years $(15 \%), 16-20$ years $(6.7 \%)$ and 21 and above $(1.7 \%)$. 


\subsection{Measures}

The study used WLB, PE and RPs scale from the seminal work of a prominent researcher who validated these measures in the context of software firms. However, the WLB scale was adapted to measure the perception of respondents for attaining a better WLB in the workplace where 18 items were utilized which evaluate WLB (Grzywacz et al., 2002; Aryee, 2005; Scullen et al., 2003) which includes flexibility at workplace, career progression, financial and non-financial rewards, teamwork and communication, and family and social support. The scale used for PE to measure the level of empowerment perceived among the executives was adapted from 10 items of the scale of Menon (1999) and Spreitzer (1995), to analyze with 4 dimensions like meaning, impact, competence and self-determination. The scale used to measure RPs utilizes 12 personalized items (Tomchin and Impara, 1992; Kim et al., 2012) to measure the extent which executives were involved with and dedicated to be remaining in a particular organization. The scale comprised of four dimensions of work culture, work support and recognition, compensation and rewards, and compatibility and autonomy. The study has implemented a five-point Likert-type scale to measure the variables ranging from strongly disagree (1) to strongly agree (5).

\subsection{Procedure}

As software professionals are diversified in nature, the survey was customized to best fit each of the organizations. It was felt that a varied approach would be more feasible for the organizations under the study and that this would help maximize response rates. Participation was granted through the booking of prior appointments and consent was obtained via questionnaire through phone calls from the organization, with the questionnaire then being shared through emails. The researcher also visited the software industries to administer the questionnaires. The participants were informed about the research purpose and were assured the answer would be treated with confidentiality. The participants were also advised regarding the voluntary nature of participation and the respective managers were reminded about the study by phone or via a visit.

\section{Data analysis}

The data were collected by using different statistical techniques, such as mean, standard deviation, Pearson's correlation and exploratory factor analysis (EFA) through the use of SPSS. In addition, AMOS software was the preferred choice for developing a hypothesized model to examine the comprehensive relationship among the constructs through confirmatory factor analysis (CFA) and structural equation modeling (SEM). The data analysis was carried out by taking a number of steps. First, each item of the variables (WLB, $\mathrm{PE}$, and RPs) is depicted as un-rotated EFA to inculcate the item dimensions. Additionally, the items were subject to EFA in order to describe each item in terms of varimax rotation and principal factors. Next, a parcel was generated following the extracted factors, which helped to improve the sample size ratio for the estimating parameters in CFA (Bentler and Chou, 1987). SEM was applied to explore the mediating role of PE among WLB and RPs. A meditation analysis was also carried out to understand whether a well-known relationship exists, by exemplifying the underlying mechanism by which one study variable affects another variable through a mediator (Byrne, 2009). The study also explored construct validity in order to examine discriminant validity, composite reliability and convergent validity. We followed the two-step procedure suggested by Anderson and Garbing (1988) to examine the hypotheses. The study first analyzed the suitability of the measurement model, and next deployed the testing of the structural model. All the analysis was carried out using ML (maximum likelihood) estimation of SEM.
Work-life balance

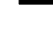


EJMS

$26,2 / 3$

112

In terms of basic and applied psychological research, this study used the technique for analyzing and testing the mediation hypothesis of Baron and Kenny (1986). In accordance with this technique, mediation is followed if: (1) the independent variable (IV) is extensively connected with the dependent variable (DV); (2) the IV is significantly associated with the mediating variable (MV), and (3) if the MV is also significantly attached with DV whenever the IV is interrelated with the DV, albeit to a significantly reduced degree (partial mediation), or when it no longer remains significant (full mediation) when it was controlled for mediators. In addition, the study also analyzed bootstrap confidence intervals for testing the mediation hypotheses (Preacher and Hayes, 2004).

\subsection{Preliminary analysis}

The table below described the specific descriptive statistics and correlation coefficients between the variables. The pattern of correlation relationship is invariable and unvarying among the hypothesized study variables, and WLB is significantly correlated with employee retention and PE. Furthermore, PE has a significant correlation with RPs. Hair et al. (2010) defined that the value of Cronbach's alpha must be situated between 0 and 1 , with 0.7 or above representing being highly suitable and significant for the analysis of the data. In this research paper, all the values of the study variables are greater than 0.7 , thus depicting the reliability of the items (see Table 1).

\section{Result and discussions}

An EFA was carried out to find the pertinent and relevant factor under the study variables where all the items of WLB were employed as measures and were subjected to factor analysis. The Kaiser-Meyer-Oklin (KMO) value is 0.834, which established the adequacy and appropriateness of the sample for factor analysis. Varimax rotation and principal component analysis (PCA) were applied to extract the factors from the 18 items. The commonalities of the loaded items replicated the amount of variance explained by each item, which lies between $56 \%$ and $81 \%$. This outcome reflected the fact that the four extracted factors accounted for $69.76 \%$ variation in the overall sample. Flexibility at the workplace elucidated a higher variance $(19.20 \%)$, which was comparable with that of family and social support, teamwork and communication, and financial and non-financial rewards $(17.27 \%, 14.29 \%$, and $14.63 \%$, respectively). Table 2 shows the four extracted factors of WLB and the factor loading of the items of WLB.

In addition, the items were used to determine PE, subject to EFA, where the value of KMO is 0.831 . The commonalities of loaded items range between $53 \%$ and $85 \%$, whereas a variation of $61.3 \%$ was displayed under three extracted factors, where self-determination has a greater variance $(28.27 \%)$, when compared with impact, meaning and competence $(22.59 \%$, $23.88 \%$ and $21.99 \%$, respectively). Table 3 displays the factor loading of the items under four extracted factors after varimax rotation for PE.

Correspondingly, a KMO was carried out on all the items to analyze RPs, subject to factor analysis, with a KMO value of 0.746 . PA PCA with varimax rotation extracted four factors from the six items that measure RPs. The commonalities of the loaded items were situated between $58 \%$ and $82 \%$. The result specified four extracted factors which accounted for a

Table 1.

Mean, standard deviation, reliability and Pearson correlation

\begin{tabular}{lrrrrrrr}
\hline Variables & Items & Mean & SD & WLB & $\alpha$ & PE & RP \\
\hline WLB & 18 & 4.21 & 0.76 & 1 & 0.783 & & \\
PE & 6 & 3.78 & 0.54 & $0.423^{* * *}$ & 0.754 & 1 & \\
RP & 6 & 3.56 & 0.68 & $0.395^{* *}$ & 0.791 & $0.405^{* * *}$ & 1
\end{tabular}

Source(s): Authors' own (based on primary data) 


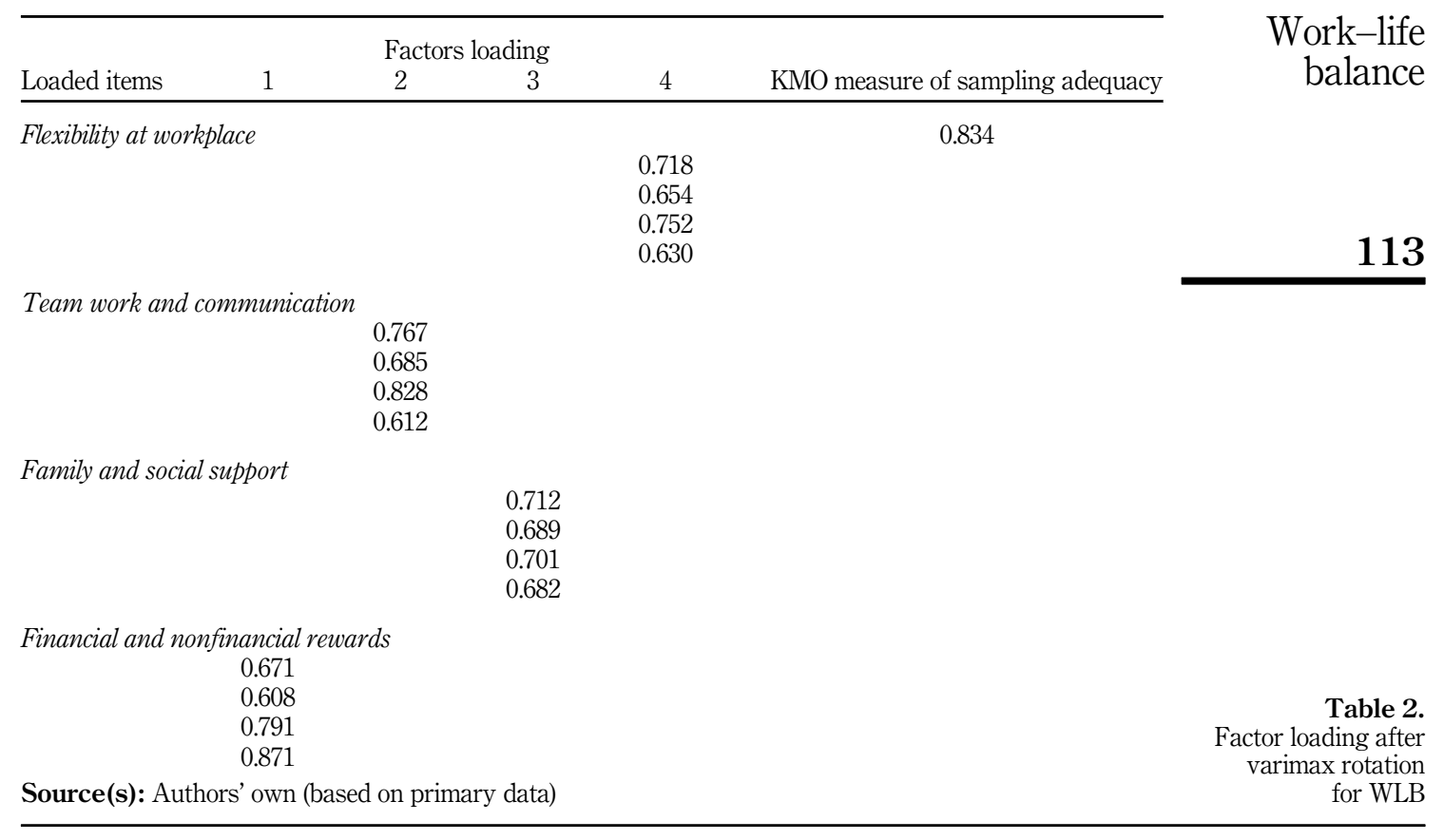

\begin{tabular}{|c|c|c|c|c|c|}
\hline & 1 & $\begin{array}{c}\text { Component } \\
2\end{array}$ & 3 & KMO measure of sampling adequacy & \\
\hline Impact & $\begin{array}{l}0.758 \\
0.852 \\
0.621 \\
0.845\end{array}$ & & & 0.831 & \\
\hline Compet & & $\begin{array}{l}0.705 \\
0.598 \\
0.812 \\
0.673\end{array}$ & & & \\
\hline Self-dete & ation & d & $\begin{array}{l}0.851 \\
0.691 \\
0.802 \\
0.764\end{array}$ & & $\begin{array}{r}\text { Table } 3 . \\
\text { Factor loading after } \\
\text { varimax rotation }\end{array}$ \\
\hline Source & Author: & ised on prima & & & for PE \\
\hline
\end{tabular}

$72.78 \%$ variation in the overall sample. Work support and recognition explained the higher variance $(28.24 \%)$, when compared with work culture, compensation and rewards, and compatibility and autonomy, respectively $(24.24 \%, 20.41 \%$, and $27.11 \%)$. Table 4 demonstrates the factor loading of the items under four extracted factors, after varimax rotation for RPs. 
EJMS

$26,2 / 3$

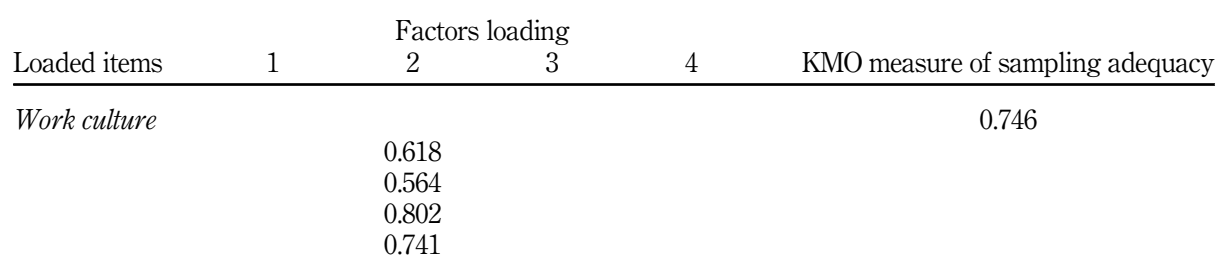

114

Support and recognition

0.876

0.856

0.818

0.725

Compatibility and autonomy

0.621

0.603

0.734

0.728

Compensation and rewards

Table 4.

Factor loading after varimax rotation for RP
0.701

0.738

0.606

0.752

Source(s): Authors' own (based on primary data)

Each latent construct was developed for unidimensionality of the items, as a precondition for generating parcels (Hall et al., 2005). For WLB, five parcels are formed by assigning four items each to dimensions, such as flexibility in the workplace, career progression and development, financial and non-financial rewards, teamwork and communication, and family and social support. In the case of PE, four parcels were developed, with four items each for meaning, impact, competence and self-determination. RPs was established for four parcels, with four items for work culture, work support and recognition, compensation and rewards, and compatibility and autonomy. Each indicator's score was evaluated with the average of items.

\subsection{Test for measurement model}

CFA was carried out by testing the measurement model, which exhibited a simple structure where the latent construct has a path for each indicator, which are also correlated with each other. The fit indices fit appropriately with the three-factor model, such as $\left(x^{2}[51]=132.407\right.$, $p<0.001, x^{2} / \mathrm{df}=2.387$;MSEA $=0.068, \mathrm{NFI}=0.93$, $\mathrm{IFI}=0.95, \mathrm{TLI}=0.952, \mathrm{CFI}=0.936$ ). As shown in Table 5 , the measurement items were also tested empirically with significant loading. The constructs of composite reliability vary between 0.73 and 0.87 , by confirming unidimensionality. Discriminant validity is the degree to which two conceptually similar concepts are distinct, which was certified with the average variance extracted (AVE) of all the constructs, which is explained in Table 6. In the confirmed model, WLB was permitted to make a direct influence on RPs, similar to the effect made by the mediator of PE.

\subsection{Examination of the mediation effect}

Table 7 of the path estimates between the constructs shows that they are all significant. Additionally, in an analysis of the direct and indirect effects between WLB and RPs on the 


\begin{tabular}{|c|c|c|c|c|c|c|}
\hline Constructs & Parcel indicators & $\begin{array}{l}\text { Standardised } \\
\text { estimates }\end{array}$ & AVE & $\mathrm{CR}$ & $p$-value & $\begin{array}{l}\text { Work-lite } \\
\text { balance }\end{array}$ \\
\hline \multirow[t]{5}{*}{ Work-life balance } & Flexibility at work place & 0.876 & \multirow[t]{5}{*}{0.768} & \multirow[t]{5}{*}{0.851} & 0.000 & \\
\hline & $\begin{array}{l}\text { Teamwork and } \\
\text { communication }\end{array}$ & 0.743 & & & 0.000 & \\
\hline & Family and social support & 0.765 & & & 0.000 & \\
\hline & Career progression & 0.771 & & & 0.000 & 115 \\
\hline & $\begin{array}{l}\text { Financial and nonfinancial } \\
\text { rewards }\end{array}$ & 0.861 & & & 0.000 & \\
\hline \multirow{4}{*}{$\begin{array}{l}\text { Psychological } \\
\text { empowerment }\end{array}$} & Meaning & 0.843 & \multirow[t]{8}{*}{0.778} & \multirow[t]{4}{*}{0.871} & 0.000 & \\
\hline & Impact & 0.762 & & & 0.000 & \\
\hline & Competence & 0.854 & & & 0.000 & \\
\hline & Self-determination & 0.732 & & & 0.000 & \\
\hline \multirow{4}{*}{$\begin{array}{l}\text { Retention of } \\
\text { professionals }\end{array}$} & Work culture & 0.763 & & \multirow[t]{4}{*}{0.753} & 0.000 & \\
\hline & Support and recognition & 0.801 & & & 0.000 & Table \\
\hline & Compensation and rewards & 0.875 & & & 0.000 & Measurement model \\
\hline & Compatibility and autonomy & 0.751 & & & 0.000 & properties \\
\hline
\end{tabular}

\begin{tabular}{lccrr}
\hline & WLB & PE & RP & \\
\hline WLB & 0.845 & & & Table 6. \\
PE & 0.745 & 0.747 & $0.845 \quad$ Discriminant validity \\
RP & 0.634 & 0.523 & 0
\end{tabular}

\begin{tabular}{llclrr}
\hline Hypotheses & Relationship & Beta coefficients & p-value & Result & \\
\hline H1 & WLB $\rightarrow$ RP & 0.614 & $*_{* * *}$ & Accepted & Table 7. \\
H2 & WLB $\rightarrow$ PE & 0.573 & ${ }^{* * * *}$ & Accepted & Hypothetical \\
H3 & PE $\rightarrow$ RP & 0.477 & $*^{* * *}$ & Accepted & inferences \\
\hline
\end{tabular}

mediated model (Table 8), evidence is found of a substantial direct effect (0.254), while the indirect effect, although less $(0.323)$ is significant, which further validates the partial mediation model. Figure 2 exhibits the mediating role of PE among WLB and RPs with the overall structural model, as well as the path coefficients.

Lastly, bootstrapping was used for 2,200 responses and was used to control the indirect effect stabilities, as well as the abnormality of data. The average estimates of bootstrap are all close to the value created for the maximum likelihood of the estimates for all the path coefficients, with the variation ranging from 0.107 to 0.317 (with an absolute average

\begin{tabular}{lll}
\hline Relationships & Relationship & $p$-value \\
\hline Total effects & 0.576 & $* * *$ \\
Direct effects & 0.253 & $* * *$ \\
Indirect effects & 0.323 & $* * *$ \\
Test of mediation & Partial &
\end{tabular}

Table 8. Result of mediation 
EJMS

$26,2 / 3$

116
Figure 2.

Overall structural model of mediation

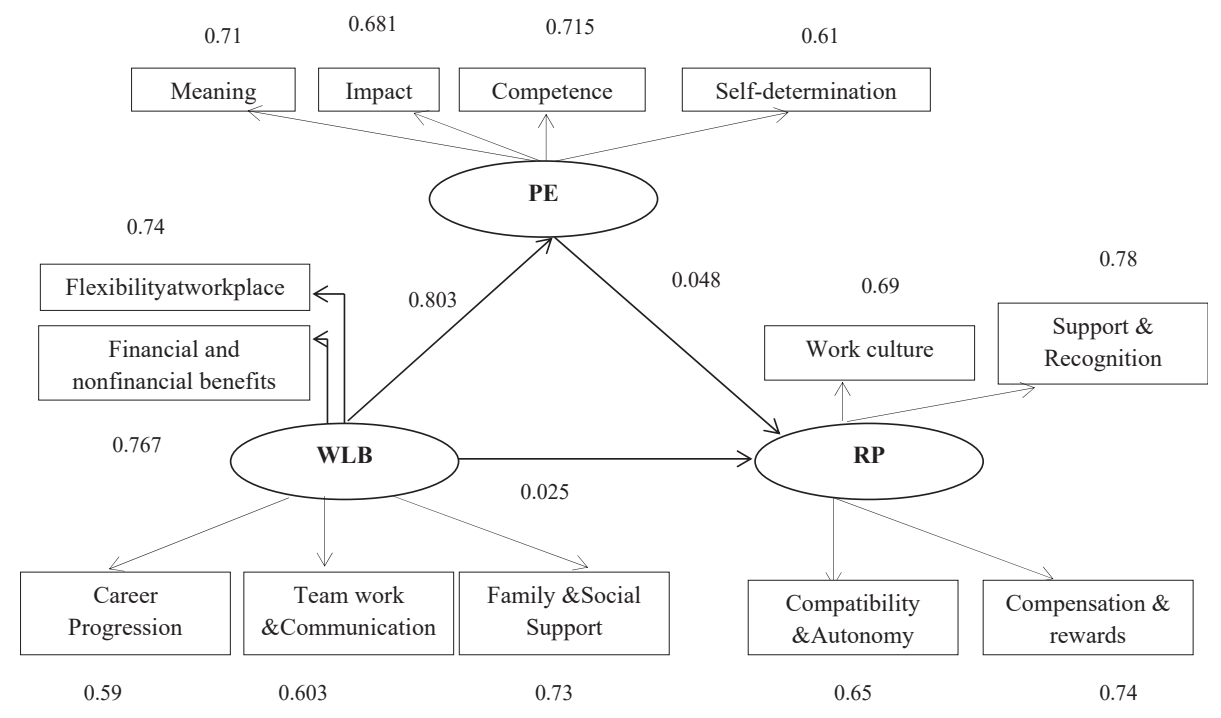

value $=0.212$ ). A $95 \%$ bias was estimated and corrected as confidence intervals incorporated at zero. The above discussion was proved by accepting Hypothesis 4.

\section{Findings of the study}

This research paper aims to explore the relationship among WLB, PE and RPs in software companies based in India. The statistical outcome of means, standard deviations, internal reliabilities and correlation among the study variables confirmed the existence of a significant and positive relationship among all of them. The pattern of correlation is consistent with the hypothesized relationships. In other words, WLB has a statistically positive relationship with the potential mediator of $\mathrm{PE}$, and also with the outcome variables of RPs. Additionally, PE has statistically a significant and positive relationship with the RPs. We found that the correlation among WLB and RPs is moderate, whereas the correlation is comparatively high between WLB and PE.

The research incorporates numerous factors which contributed to the factor loading of the study variables, where WLB is comprised of five factors, namely flexibility in the workplace, family and social support, teamwork and communication, career progression, and financial and non-financial rewards, which supports the previous findings (Kossek and Lautsch, 2018; Neumann et al., 2018; Lee et al., 2018; Sexton et al., 2017; Russo et al., 2016). The study went on to analyze five variables which fall under WLB together, in order to reveal RPs and PE. RPs is comprised of four factors, namely support and recognition, work culture, compensation and rewards, and compatibility and autonomy, which thus reaffirm the finding proposed by Pathak and Srivastav (2017). PE was constituted with the following factors: meaning, impact, competency and self-determination, which confirmed the findings of Spreitzer (1995). A parcel was created through EFA to analyze the CFA.

The analysis of the SEM result showed that WLB has a significant and positive relationship with employee retention in software companies. WLB plays a major role in increasing executives' involvement and their decision whether to stay in or leave software companies. Professionals can exhibit a better level of WLB and RPs, demonstrating flexibility in the workplace, family and social support, teamwork and communication, career 
progression, and financial and non-financial rewards. This result validates Hypothesis 1, which was supported in the previous studies of Deery (2008). Those professionals with a high degree of PE are able to increase the sense of personal control and motivate themselves to become involved with the assignment can exhibit the ability to maintain and develop a good degree of WLB. This result is connected with the Hypothesis 2, which in turn validates the previous research and confirms the existence of the positive effect of WLB on PE (Akdag, 2012). The study's findings also reflected the significant relation of PE with RPs, which corroborates Hypothesis 3 . This paper focused on the perception that empowerment is a vital and key aspect, which directly affects physical and mental well-being, and WLB which indirectly affects the RPs (Akdag, 2012). Furthermore, the outcome of the research proved the partial mediating effect of PE on the relationship between WLB and RPs and also validated Hypothesis 4, furthering the body of literature on mediating mechanisms of PE. Accordingly, the incorporation of psychological empowering professionals and better WLB can have an intensifying effect on employee retention.

\section{Managerial implications}

The research highlights that better WLB could promote the cognitive and psychological aspects of software professionals in IT companies. If an organization can support a flexible work schedule that ensures satisfaction and pleasure in the work environment, this will in turn enhance a better level of WLB among software professionals. HR professionals need to support teamwork and positive communication, with the help of suggestions, counsel, feedback and the giving of positive criticism by team leaders, supervisors and managers, as well as from peers, that will have the effect of improving the level of WLB, which in turn will make them more responsible in carrying out their work assignments. Other dimensions, such as financial and non-financial benefits received by professionals based on the prevailing market rates, comprising fair overtime rates and other financial benefits, which varies from organization to organization, as well as non-financial rewards such as recognition, autonomy, praise and rewards will all encourage and empower executives and will have the effect of developing an improved level of commitment, as well as better job performance. Furthermore, family and social support, such as supportive family members, good working relationships, and fair treatment by peers and supervisor will improve the degree of the WLB of IT professionals. Although WLB initiatives are very scarce, this study provides ample evidence for designing strategies and structures to enhance the WLB of software professionals. Team leaders and HR professionals must encourage the psychological well-being and WLB among executives, although these tend to fail repeatedly in the practical realization of the concept. This research provides a theoretical outline for the forecasting and implementation of WLB efforts among IT companies.

Software companies should emphasis psychological well-being and empowerment as an imperative HR strategy which supports a strong policy and guidelines for enforcing the same. In order to develop a positive work environment and a balanced life in software companies, team leaders and HR managers should engage their professionals to face challenges that could harmonize and enlarge the abilities, knowledge and skills required for completing projects and other job requirements. Nevertheless, professionals should have autonomy for decision-making in project management and the handling of customers and clients, as well as for the requirements of appropriate time and information. This study investigates the mediating relationship of PE among WLB and RPs, and also the mediating constructs consisting of the four components of meaning, impact, competence and self-determination, which partially demonstrates mediation among the variables. These components reflect intrinsic task motivation by replicating a sense of self-awareness and control in relation to the work role and amplify a positive attitude, task performance, leadership, group decisions and 
EJMS

$26,2 / 3$

118

organizational design. Few studies exist which relate to the meditational relationship of PE among variables, whereas this study offers extensive evidence for the HR professionals for the development of strategies and structures that are capable of increasing the level of $\mathrm{PE}$ for enhancing WLB among software professionals.

Software companies must endorse PE to enhance the level of perceived WLB for executives in relation to work spirit through dynamism and independence that will promote WLB tremendously. Furthermore, when organizations promote a sense of empowerment, their professionals might be reciprocated with more dedication, enthusiasm and commitment. However, the impact of PE on WLB could enhance the degree of loyalty, integrity, allegiance and trustworthiness among professionals that could well influence employee retention. This emphasis on symbolic affiliation could be a win-win strategy for software companies. This approach can offer momentous insights for team leaders, software professionals, directors, consultants, managers and HR practitioners alike to design a suitable strategy and bring about the appropriate intervention required to create a professional life that is more significant and value driven.

\section{Limitation and future directions}

This research has several limitations. For example, the scope of the study is limited to professionals of IT companies located on the eastern and western sides of India, which narrows down the scope in terms of the overall outcomes. The study was based on a crosssectional approach, where information was gathered from individual respondents at a particular point of time. Accordingly, the outcome could fluctuate in a longitudinal study where the progress is assessed over a period. However, in carrying out this research, the author faced hesitation and unwillingness among the various respondents of the respective organizations to participate in the survey. The sample of the study is thus relatively small for providing a robust model, and incorporating a larger sample of software professionals would be valuable in extending and cross validating the present findings of IT companies in India. The coronavirus disease 2019 (COVID-19) pandemic affected the world drastically, and as the study was totally carried out before COVID-19, the author intends to carry out further research to explore the effect of COVID-19 on the same constructs in the future. Consequently, further research may be carried out with software professionals from other developing regions and other developing countries to validate the research findings and suggestions. A comparative analysis could be designed for use among other industry sectors, such as the automobile, business process outsourcing (BPO), healthcare and tourism industries. The research has highlighted a theoretical structure that is drawn from empirical research, however future studies could emphasize other constructs, such as work-life quality, psychological well-being and workplace empowerment, and could analyze their role in improving WLB and the RPs. Additionally, further research could also validate the role of other mediators, such as employee commitment, value congruence and transformational leadership to explain the association between WLB and the RPs, and accordingly generate useful outcomes.

\section{Conclusion}

WLB can facilitate the success of an organization through the adoption of a culture of synergy, self-awareness, collaboration, and a sense of well-being, autonomy and partnership, all of which enhances the level of PE among executives. In addition, a high level of empowerment has been seen to help professionals to be focused and encourages them to be dedicated to bringing about the success of the organization. When WLB is allied with PE, it generates a synergistic effect on the attitude of professionals, and the organization's 
outcomes. In the long run, professionals who are stimulated intrinsically in body, mind and spirit are better prepared to face challenges and pressure at work. This study represents an effort to incorporate professionals as a core and long-term asset of the software industry. This can only be achieved by embedding high standards of practice and WLB initiatives in strategic planning at both the organizational and governance levels.

\section{References}

Akdag, F. (2012), "Impact of empowerment on work-life balance and employee well-being",Cambridge Business and Economics Conference, Cambridge, UK.

Akila, R. (2012), "A study on employee retention among executives at BGR energy systems Ltd, Chennai", International Journal of Marketing, Financial Services and Management Research, Vol. 1 No. 9, pp. 18-32.

Anderson, J.C. and Gerbing, D.W. (1988), "Structural equation modeling in practice: a review and recommended two-step approach", Psychological Bulletin, Vol. 103 No. 3, pp. 411-423.

Aryee, S. (2005), "Rhythms of life: antecedents and outcomes of work-family balance in employed parents", Journal of Applied Psychology, Vol. 90 No. 1, pp. 132-146.

Avolio, B.J. (1999), Full Leadership Development: Building the Vital Forces in Organization, Sage Publications, pp. 191-199.

Baron, R.M. and Kenny, D.A. (1986), "The moderator-mediator variable distinction in social psychological research: conceptual, strategic, and statistical considerations", Journal of Personality and Social Psychology, Vol. 51 No. 6, pp. 1173-1182.

Baruch, Y. (2006), "Career development in organizations and beyond: balancing traditional and contemporary viewpoints", Human Resource Management Review, Vol. 16, pp. 125-138.

Bentler, P.M. and Chou, C.P. (1987), "Practical issues in structural modeling", Sociological Methods and Research, Vol. 16 No. 1, pp. 78-117.

Bond, S. (2004), "Organisational culture and work-life conflict in the UK", International Journal of Sociology and Social Policy, Vol. 24 No. 12, pp. 1-24.

Brooks, B.A. and Anderson, M.A. (2005), "Defining quality of nursing work life", Nursing Economics, Vol. 23 No. 6, pp. 319-326.

Byrne, B.M. (2009), Structural Equation Modeling with AMOS: Basic Concepts, Applications, and Programming, 2nd ed., Routledge, NewYork.

Cegarra-Leiva, D., Sánchez-Vidal, M.E. and Cegarra-Navarro, J.G. (2012), "Understanding the link between work life balance practices and organisational outcomes in SMEs: the mediating effect of a supportive culture", Personnel Review, Vol. 41 No. 3, pp. 359-379.

Clarke, M.C., Koch, L.C. and Hill, E.J. (2004), "The work-family interface: differentiating balance and fit”, Family and Consumer Sciences Research Journal, Vol. 33 No. 2, pp. 121-140.

Cooke, F.L. and Jing, X. (2009), "Work-life balance in China: sources of conflicts and coping strategies", NHRD Network Journal, Vol. 2 No. 6, pp. 18-28.

Cummings, T. and Worley, C. (2009), Organization Development and Change, 9th ed., South-Western Cengage Learning, Mason, $\mathrm{OH}$.

De Klerk, S. and Stander, M.W. (2014), "Leadership empowerment behavior, work engagement and turnover intention: the role of psychological empowerment", Journal of Positive Management, Vol. 5 No. 3, pp. 28-45.

De Zoysa, W.M. and Sivalogathasan, V. (2018), "The mediation effect of work-life balance on the relationship between psychological empowerment and job satisfaction among female bank employees of Sri Lanka”, Management Issues, Vol. 3 No. 1, pp. 1-8.

Deery, M. (2008), "Talent management, work-life balance and retention strategies", International Journal of Contemporary Hospitality Management, Vol. 20 No. 7, pp. 792-806. 
EJMS

$26,2 / 3$

Deery, M. and Jago, L. (2015), "Revisiting talent management, work-life balance, and retention strategies", International Journal of Contemporary Hospitality Management, Vol. 27 No. 3, pp. 453-472.

Delecta, P. (2011), "Work life balance", International Journal of Current Research, Vol. 3 No. 4, pp. 186-189.

Dewettinck, K. and van Ameijde, M. (2011), "Linking leadership empowerment behavior to employee attitudes and behavioral intentions: testing the mediating role of psychological empowerment", Personnel Review, Vol. 40 No. 3, pp. 284-305.

Dust, S.B., Resick, C.J., Margolis, J.A., Mawritz, M.B. and Greenbaum, R.L. (2018), "Ethical leadership and employee success: examining the roles of psychological empowerment and emotional exhaustion”, The Leadership Quarterly, Vol. 29 No. 5, pp. 570-583.

Edwards, J.R. and Rothbard, N.P. (2000), "Mechanisms linking work and family: clarifying the relationship between work and family constructs", Academy of Management Review, Vol. 25 No. 1, pp. 178-199.

Elmuti, D. (1997), "Self-managed work teams approach creative management tool or a fad?", Management Decision, Vol. 35 No. 3, pp. 233-239.

Friedman, S.D. and Westring, A. (2015), "Empowering individuals to integrate work and life: insights for management development", Journal of Management Development, Vol. 34 No. 3, pp. 299-315.

Galea, C., Houkes, I. and De Rijk, A. (2014), "An insider's point of view: how a system of flexible working hours helps employees to strike a proper balance between work and personal life", The International Journal of Human Resource Management, Vol. 25 No. 8, pp. 1090-1111.

Grealish, A., Tai, S., Hunter, A., Emsley, R., Murrells, T. and Morrison, A.P. (2017), "Does empowerment mediate the effects of psychological factors on mental health, well-being, and recovery in young people?", Psychology and Psychotherapy: Theory, Research, and Practice, Vol. 90 No. 3, pp. 314-335.

Greenblatt, E. (2002), “Work/life balance: wisdom or whining”, Organizational Dynamics, Vol. 31 No. 2, pp. 177-193.

Greenhaus, J.H. and Powell, G.N. (2000), "When work and family collide: choices and conflict between competing role demands", in Academy of Management Proceedings, Academy of Management, Briarcliff Manor, NY, Vol. 20 No. 1, pp. B1-B6.

Grzywacz, J.G., Almeida, D.M. and McDonald, D.A. (2002), "Work-family spillover and daily reports of work and family stress in the adult labor force”, Family Relations, Vol. 51 No. 1, pp. 28-36.

Haider, M., Rasli, A., Akhtar, S., Yusoff, R.B.M., Malik, O.M., Aamir, A. and Tariq, F. (2015), "The impact of human resource practices on employee retention in the telecom sector", International Journal of Economics and Financial Issues, Vol. 5 No. 1, pp. 63-69.

Hair, J.F., Celsi, M., Ortinau, D.J. and Bush, R.P. (2010), Essentials of Marketing Research, Vol. 2, McGraw-Hill/Irwin, New York, NY.

Hall, R.J., Dyer, N.G. and Hanges, P.J. (2005), "Applying multilevel confirmatory factor analysis techniques to the study of leadership", The Leadership Quarterly, Vol. 16 No. 1, pp. 149-167.

Ickes, S.B., Wu, M., Mandel, M.P. and Roberts, A.C. (2018), "Associations between social support, psychological well-being, decision making, empowerment, infant and young child feeding, and nutritional status in Ugandan children ages 0 to 24 months", Maternal and Child Nutrition, Vol. 14 No. 1, pp. 1-11.

Iqbal, S. and Hashmi, M.S. (2015), "Impact of perceived organizational support on employee retention with mediating role of psychological empowerment”, Pakistan Journal of Commerce and Social Sciences, Vol. 9 No. 1, pp. 18-34.

Jha, S. (2010), "Need for growth, achievement, power, and affiliation: determinants of psychological empowerment”, Global Business Review, Vol. 11 No. 3, pp. 379-393. 
Joo, B.K. and Jo, S.J. (2017), "The effects of perceived authentic leadership and core self-evaluations on organizational citizenship behavior: the role of psychological empowerment as a partial mediator", Leadership and Organization Development Journal, Vol. 38 No. 3, pp. 463-481.

Jung, Y. and Takeuchi, N. (2018), "A lifespan perspective for understanding career self-management and satisfaction: the role of developmental human resource practices and organizational support", Human Relations, Vol. 71 No. 1, pp. 73-102.

Kanter, R. (1977), Men, and Women of the Corporation, Basic Books, New York, NY.

Kanwar, Y.P.S., Singh, A.K. and Kodwani, A.D. (2009), "Work-life balance and burnout as predictors of job satisfaction in the IT-ITES industry", Vision, Vol. 13 No. 2, pp. 1-12.

Kim, M. and Beehr, T.A. (2018), "Organization-based self-esteem and meaningful work mediate effects of empowering leadership on employee behaviors and well-being", Journal of Leadership and Organizational Studies, Vol. 25 No. 4, pp. 385-398.

Kim, G.H., Kim, J. and Limb, J. (2012), "Mediating effect of psychological empowerment in relationship between professional self-concept and burnout in psychiatric nurses", Journal of Korean Academy of Psychiatric and Mental Health Nursing, Vol. 21 No. 3, pp. 229-237.

Koberg, C.S., Boss, R.W., Senjem, J.C. and Goodman, E.A. (1999), "Antecedents and outcomes of empowerment: empirical evidence from the health care industry", Group and Organization Management, Vol. 24 No. 1, pp. 71-91.

Kohn, M.L. and Schooler, C. (1983), Work and Personality: an Inquiry into the Impact of Social Stratification, Ablex Pub, pp. 43-68.

Kossek, E.E. and Laatsch, B.A. (2018), "Work-life flexibility for whom? Occupational status and worklife inequality in upper, middle, and lower level jobs", Academy of Management Annals, Vol. 12 No. 1, pp. 5-36.

Landauer, J. (1997), "Bottom-line benefits of work/life programs”, HR FOCUS, pp. 3-4.

Laschinger, H.K.S., Grau, A.L., Finegan, J. and Wilk, P. (2010), "New graduate nurses' experiences of bullying and burnout in hospital settings", Journal of Advanced Nursing, Vol. 66 No. 12, pp. 2732-2742.

Lee, D.J., Grace, B.Y., Sirgy, M.J., Singhapakdi, A. and Lucianetti, L. (2018), "The effects of explicit and implicit ethics institutionalization on employee life satisfaction and happiness: the mediating effects of employee experiences in work life and moderating effects of work-family life conflict", Journal of Business Ethics, Vol. 147 No. 4, pp. 855-874.

Lockwood, N.R. (2003), "Work/life balance. Challenges and solutions”, SHRM Research, USA, pp. 34-49.

Loretto, W., Platt, S. and Popham, F. (2010), "Workplace change and employee mental health: results from a longitudinal study", British Journal of Management, Vol. 21 No. 2, pp. 526-540.

Macey, W.H., Schneider, B., Barbera, K.M. and Young, S.A. (2009), Employee Engagement: Tools for Analysis, Practice and Competitive Advantage, John Wiley \& Sons, WestSussex.

Mak, B.L. and Sockel, H. (2001), "A confirmatory factor Analysis of IS employee motivation and retention”, Information and Management, Vol. 38 No. 5, pp. 265-276.

McEvoy, G.M. and Cascio, W.F. (1985), "Strategies for reducing employee turnover: a meta-analysis", Journal of Applied Psychology, Vol. 70 No. 2, pp. 342-353.

Meng, L., Jin, Y. and Guo, J. (2016), "Mediating and/or moderating roles of psychological empowerment", Applied Nursing Research, Vol. 30, May, pp. 104-110, doi: 10.1016/j.apnr.2015. 11.010, Epub 2015 Nov 18. PMID: 27091263.

Menon, S.T. (1999), "Psychological empowerment: definition, measurement, and validation”, Canadian Journal of Behavioural Science/Revue Canadienne des Sciences du comportement, Vol. 31 No. 3, pp. 161-174. 
EJMS

$26,2 / 3$

122

Miguel, M.C., Ornelas, J.H. and Maroco, J.P. (2015), "Defining psychological empowerment construct: analysis of three empowerment scales", Journal of Community Psychology, Vol. 43 No. 7, pp. 900-919.

Morris, M.L. and Madsen, S.R. (2007), "Advancing work-life integration in individuals, organizations, and communities", Advances in Developing Human Resources, Vol. 9 No. 4, pp. $439-454$.

Neumann, J.L., Mau, L.W., Virani, S., Denzen, E.M., Boyle, D.A., Boyle, N.J. and Majhail, N.S. (2018), "Burnout, moral distress, work-life balance, and career satisfaction among hematopoietic cell transplantation professionals”, Biology of Blood and Marrow Transplantation, Vol. 24 No. 4, pp. 849-860.

O'Leary-Kelly, A.M., Martocchio, J.J. and Frink, D.D. (1994), "A review of the influence of group goals on group performance”, Academy of Management Journal, Vol. 37 No. 5, pp. 1285-1301.

Pathak, D. and Srivastava, S. (2017), "What makes employees stay? Role of psychological empowerment in organizational commitment-turnover intentions relationship: a study on Indian managers", International Journal of Indian Culture and Business Management, Vol. 14 No. 2, pp. 180-197.

Patrick, a. and Laschinger, H.K.S. (2006), "The effect of structural empowerment and perceived organizational support on middle-level nurse manager's role satisfaction”, Journal of Nursing Management, Vol. 14 No. 1, pp. 13-22.

Pocock, B. (2005), "Work-life balance in Australia: limited progress, dim prospects", Asia Pacific Journal of Human Resources, Vol. 43 No. 2, pp. 198-209.

Preacher, K.J. and Hayes, A.F. (2004), "SPSS and SAS procedures for estimating indirect effects in simple mediation models", Behavior Research Methods, Instruments, and Computers, Vol. 36 No. 4, pp. 717-731.

Propp, K.M., Apker, J., Zabava Ford, W.S., Wallace, N., Serbenski, M. and Hofmeister, N. (2010), "Meeting the complex needs of the health care team: identification of nurse-team communication practices perceived to enhance patient outcomes", Qualitative Health Research, Vol. 20 No. 1, pp. 15-28.

Quinn, R.E. and Spreitzer, G.M. (1997), "The road to empowerment: seven questions every leader should consider", Organizational Dynamics, Vol. 26 No. 2, pp. 37-49.

Robbins, T.L., Crino, M.D. and Fredendall, L.D. (2002), "An integrative model of the empowerment process", Human Resource Management Review, Vol. 12 No. 3, pp. 419-443.

Roger, S.A. and Padgett, M.Y. (2004), "The impact of utilizing a flexible work schedule on the perceived career advancement potential of women”, Human Resource Development Quarterly, Vol. 15 No. 1, pp. 89-106.

Ross, C.E. and Mirowsky, J. (2002), "Family relationships, social support and subjective life expectancy", Journal of Health and Social Behavior, Vol. 43 No. 4, pp. 469-489.

Russo, M., Shteigman, A. and Carmeli, A. (2016), "Workplace and family support and work-life balance: implications for individual psychological availability and energy at work", The Journal of Positive Psychology, Vol. 11 No. 2, pp. 173-188.

Sankar, T. and Bhatnagar, J. (2010), "Work life balance, employee engagement, emotional consonance/ dissonance, and turnover intention”, Indian Journal of Industrial Relations, Vol. 46 No. 1, pp. 74-87.

Santhanam, N., Kumar, J.R., Kumar, V. and Saha, R. (2021), "Employee turnover intention in the milieu of human resource management practices: moderating role of work-life balance", International Journal of Business Innovation and Research, Vol. 24 No. 1, pp. 57-75.

Scullen, S.E., Mount, M.K. and Judge, T.A. (2003), "Evidence of the construct validity of developmental ratings of managerial performance”, Journal of Applied Psychology, Vol. 88 No. 1, pp. 50-66. 
Sexton, J.B., Schwartz, S.P., Chadwick, W.A., Rehder, K.J., Bae, J., Bokovoy, J. and Profit, J. (2017), “The associations between work-life balance behaviors, teamwork climate, and safety climate", $B M J$ Qual Saf, Vol. 26 No. 8, pp. 632-640.

Sheridan, J.E. (1992), "Organizational culture and employee retention”, Academy of Management Journal, Vol. 35 No. 5, pp. 1036-1056.

Spreitzer, G.M. (1995), "Psychological empowerment in the workplace: dimensions, measurement, and validation", Academy of Management Journal, Vol. 38 No. 5, pp. 1442-1465.

Spreitzer, G.M., Kizilos, M.A. and Nason, S.W. (1997), "A dimensional analysis of the relationship between psychological empowerment and effectiveness satisfaction, and strain", Journal of Management, Vol. 23 No. 5, pp. 679-704.

Sun, X. (2016), "Psychological empowerment on job performance-mediating effect of job satisfaction”, Psychology, Vol. 7 No. 04, pp. 584-591.

Thomas, K.W. and Velthouse, B.A. (1990), "Cognitive elements of empowerment: an "interpretive" model of intrinsic task motivation", Academy of Management Review, Vol. 15 No. 4, pp. 666-681.

Tomchin, E.M. and Impara, J.C. (1992), “Unraveling teachers' beliefs about grade retention”, American Educational Research Journal, Vol. 29 No. 1, pp. 199-223.

Vallone, G.E.J. and Ensher, E.A. (1998),“The effect of work and personal life conflict and organizational support", Academy of Management Conference, San Diego, CA.

Van Laar, D., Edwards, J.A. and Easton, S. (2007), "The work-related quality of life scale for healthcare workers", Journal of Advanced Nursing, Vol. 60 No. 3, pp. 325-333.

Violanti, J.M. and Aron, F. (1994), "Ranking police stressors", Psychological Reports, Vol. 75 No. 2, pp. 824-826.

Walumbwa, F.O. and Lawler, J.J. (2003), "Building effective organizations: transformational leadership, collectivist orientation, work-related attitudes and withdrawal behaviors in three emerging economies", Journal of Human Resource Management, Vol. 14 No. 7, pp. 1083-1101.

Yilmaz, A. and Bardakoglu, O. (2017), "The impacts of perceived organizational prestige and organization identification on turnover intention: the mediating effect of psychological empowerment", Current Issues in Tourism, Vol. 20 No. 14, pp. 1510-1526.

Yukl, G. (2010), Leadership in Organizations, 7th ed., Pearson, Upper Saddl, NJ.

Zedeck, S. and Mosier, K.L. (1990), "Work in the family and employing organization", American Psychologist, Vol. 45 No. 2, pp. 240-264.

\section{Corresponding author}

Ansumalini Panda can be contacted at: ansumalini@gmail.com

For instructions on how to order reprints of this article, please visit our website:

www.emeraldgrouppublishing.com/licensing/reprints.htm

Or contact us for further details: permissions@emeraldinsight.com 